\title{
RANCANG BANGUN APLIKASI INVENTORY ALAT TULIS KERJA PADA SMK PURNA USAHA TAMA
}

\author{
Ezra Assyadan \\ Program Studi Informatika, Fakultas Teknik dan Ilmu Komputer, Universitas Indraprasta PGRI \\ Jalan Raya Tengah No 80, Kelurahan Gedong, Pasar Rebo, Jakarta Timur \\ Ezraassyadan167@gmail.com
}

\begin{abstract}
Abstrak
Pada inventory alat tulis kerja di Sekolah SMK Purna Usaha Tama untuk bagian staf tata usaha segala kegiatan keluar - masuk barang masih terbilang manual dengan pencatatan dan rekapitulasi menggunakan buku arsip. Selama ini inventory alat tulis kerja di sekolah belum memiliki aplikasi khusus untuk inventory alat tulis kerja sehingga belum sepenuhnya terkomputerisasi. Bagaimana merancang aplikasi yang cepat, tepat dan akurat untuk inventory alat tulis kerja (ATK) agar dapat membantu kinerja staf TU dan sekolah secara efektif juga efisien. Penelitian ini menggunakan tema SMBD dengan metode kuantitatif untuk memproses data berupa angka penghitungan stok barang dan keluar-masuk barang, dengan penggunaanya single user sebagai admin pada bagian staff tata usaha. Dengan adanya aplikasi inventory barang, manajemen dan monitoring kegiatan barang dalam gudang akan tersimpan secara rapih, aman dan akurat dalam database yang bersifat sistematis. Meningkatkan kinerja kegiatan karyawan demi menyeimbangkan perkembangan teknologi industri 4.0 dalam segi manajemen maupun monitoring kegiatan inventory barang juga membentuk sistem yang lebih maju dari sebelumnya.
\end{abstract}

Kata kunci: Inventaris, aplikasi, pemantauan

\begin{abstract}
In the inventory of stationery work at the school of SMK Purna Usaha Tama for the staff of the administration of all activities out-of-entry goods still numbered manually with the recording and recapitulation using the archive book. During this work stationery inventory at school has not had a special application for work stationery inventory so it has not been fully computerized. How to design a fast, precise and accurate application for work stationery inventory (ATK) in order to help the performance of TU and school staff effectively is also efficient. . This research uses SMBD theme with quantitative method to process data in the calculation of stock goods and entry of goods, with the use of single user as admin in the administration staff. With the application of inventory goods, management and monitoring of goods activities in the warehouse will be stored neatly, securely and accurately in a systematic database. Improve the performance of employees ' activities to balance the development of industrial Technology 4.0 in terms of management and the monitoring of goods inventory activities also form a system that is more advanced than before.
\end{abstract}

Keywords: inventory, application, monitoring

\section{PENDAHULUAN}

Perkembangan zaman era industri 4.0 terutama pada saat ini sistem informasi yang menggunakan teknologi komputer terlihat sangat berkembang. Dimana perkembangan ini dapat memudahkan kita untuk melakukan pengolahan data yang dapat menghemat waktu, ruang, dan biaya. Hasil suatu informasi teknologi yang diperoleh akan sangat memuaskan, berguna dan bermanfaat bagi perusahaan atau instansi yang menggunakannya. Pengolahan data dan informasi secara cepat, tepat dan efisien adalah hal penting yang dibutuhkan bagi setiap perusahaan atau instansi, seperti halnya pada SMK Purna Usaha Tama Depok merupakan lembaga pendidikan menengah keatas swasta. Pada Inventaris alat tulis kerja di Sekolah SMK Purna Usaha Tama untuk bagian staf tata usaha segala kegiatan keluar-masuknya barang masih terbilang manual dengan pencatatan dan rekapitulasi menggunakan buku arsip. Selama ini inventory alat tulis kerja di sekolah belum memiliki aplikasi khusus untuk inventaris barang sehingga belum sepenuhnya terkomputerisasi. Menurut (Herjanto, 2010) Inventory adalah bahan atau barang yang disimpan yang akan digunakan untuk memenuhi tujuan tertentu, 
misalnya untuk digunakan dalam proses produksi atau perakitan, untuk dijual kembali, atau untuk suku cadang dari suatu peralatan atau mesin. Menurut (Haming \& Nurnajamuddin, 2014)“Inventory adalah sumber daya ekonomi fisik yang perlu diadakan dan pelihara untuk menunjang kelancaraan produksi, meliputi bahan baku (raw material),

Tujuan dilakukan penelitian ini adalah untuk merancang aplikasi yang cepat, tepat dan akurat untuk inventory alat tulis kerja (ATK). Menurut (Wicaksono, 2011) Perancangan adalah sebuah proses untuk mendefinisikan sesuatu yang akan dikerjakan dengan mengunakan teknik yang bervariasi serta didalamnya melibatkan deskripsi mengenai arsitektur serta detail mengenai komponen dan juga keterbatasan yang akan dialami dalam proses pengerjaannya. juga efisien. Selain itu tujuan dari penelitian ini adalah merancangan aplikasi yang dapat memberi kemudahan dalam penyimpanannya inventory alat tulis kerja (ATK)secara cepat dan akurat. Menurut (Yanto, 2016) Basis data terdiri dari 2 kata, yaitu basis dan data. Basis dapat diartikan sebagai markas, gudang, tempat berkumpul. Sedangkan data adalah fakta yang mewakili suatu objek seperti manusia, barang, hewan peristiwa, keadaan dan sebagainya, yang direkam dalam bentuk angka, huruf, simbol, teks, gambar, bunyi atau kombinasinya".

Manfaat dari penelian ini adalah aplikasi yang dibuat dapat dapat membantu kinerja staf TU dan sekolah secara efektif juga efisien, memberi kemudahan pengolahan inventory alat tulis kerja (ATK) dalam penyimpanannya secara cepat dan akurat, dapat mengoptimalkan kinerja para staf TU, dan sekolah dalam menangani berkas-berkas administratif data pengolahan inventory.

\section{PENELITIAN RELEVAN}

Penelitian yang dilakukan oleh Anna Fitriya( 2015) dengan judul Sistem Inventory Barang Dengan Teknologi Ajax. Hasil dari penelitian ini penggunaan teknologi AJAX dapat membuat sistem lebih ringan diakses, dengan adanya sistem ini, pihak toko dapat memperoleh informasi tentang barang yang masih tersedia, barang yang habis atau barang yang hampir habis dengan mudah dan cepat.

Penelitian yang dilakukan oleh Rina Kristinugraini (2014) dengan judul Sistem Informasi Inventory Obat Menggunakan Metode Fifo Pada Apotik Mugi Waras Semarang Berbasis Clien Server. Hasil dari penelitian ini berdasarkan sistem informasi inventory obat yang diusulkan, maka penyajian laporan persediaan akan lebih cepat dan mudah jika dibandingkan dengan sistem yang berjalan saat ini.

\section{METODE PENELITIAN}

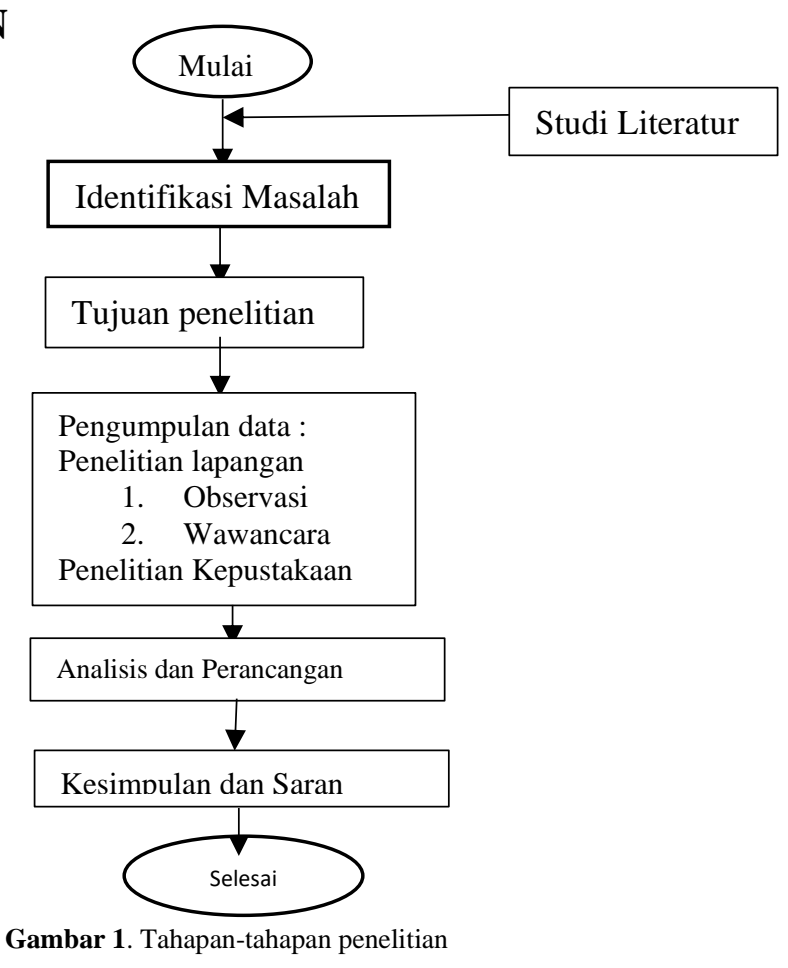




\section{a. Analisis Kebutuhan}

Bertujuan untuk mendapatkan data-data yang akan digunakan sebagai masukan dari sistem (perangkat lunak) dan memperoleh data yang berhubungan dengan skripsi ini. Proses pembuatan perancangan program menggunakan pemrograman Java serta didukung peralatan lainnya. Kita merancang harus mengetahui apa saja yang pengguna inginkan dan bagaimana mereka melakukan cara memenuhi keinginannya.

\section{b. Perancangan Sistem}

Dalam tahap desain ini, dilakukan perancangan untuk aplikasi yang akan dibuat, yang terdiri dari : Perancangan Proses mengguakan DFD (Data Flow Diagram) dan struktur data.

Perancangan Database menggunakan ERD (Entity Relationship Diagram) beserta analisa adanya menggunakan teknik Normalisasi dan Spesifikasi database.

\section{HASIL DAN PEMBAHASAN}

\section{Proses Bisnis Sistem Berjalan}

\section{Pengolahan Data Pemesanan Barang}

Staf tata usaha melakukan pengecekan barang, jika stok barang adayang habis maka staf tata usaha melakukan rekap barang yang ingin dibeli kemudian ditanda tangani oleh kepala sekolah dan kertas tersebut diserahkan secara langsung ke pihak supplier agar segera dikirim pesanan barang tersebut.

\section{Pengolahan Data Barang Masuk}

Staf tata usaha melakukan penerimaan barang dengan cara manual yaitu menggunakan buku besar penerimaan alat tulis kerja, diawali dengan pengecekan jumlah barang bersama dengan pihak supplier agar tidak terjadi kesalahan, kemudian dicatat ke dalam buku besar penerimaan alat tulis kerja sesuai dengan jumlah barang yang dikirim.

\section{Pengolahan Data Barang Keluar}

Setiap karyawan yang menggunakan alat tulis kerja diwajibkan mengisi buku pengeluaran alat tulis kerja dengan jelas yang berisikan NIK, nama karyawan, jumlah, nama barang, tanggal pengambilan dan paraf, setelahnya staf tata usaha akan merekap data barang-barang yang sudah diambil oleh karyawan.

\section{Laporan}

Staff tata usaha wajib membuat laporan dengan periode bulan, diantaranya laporan penerimaan, laporan pengeluaran, dan laporan stok. Yang diserahkan kepada kepala sekolah dan ditanda tangani.

\section{Proses Bisnis Sistem Diusulkan}

\section{Diagram Konteks sistem yang diusulkan}

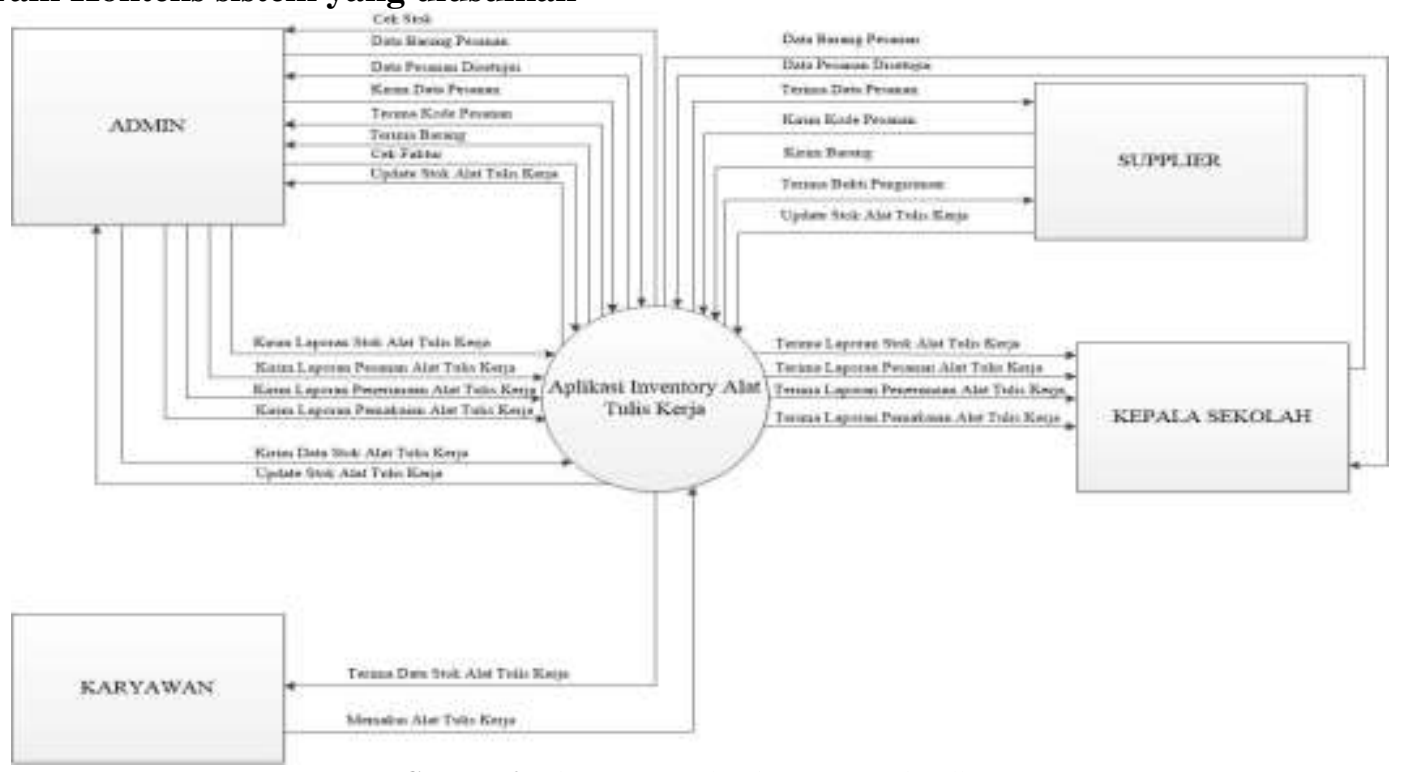

Gambar 2. Diagram Konteks Sistem yang Diusulkan 


\section{Diagram Nol}

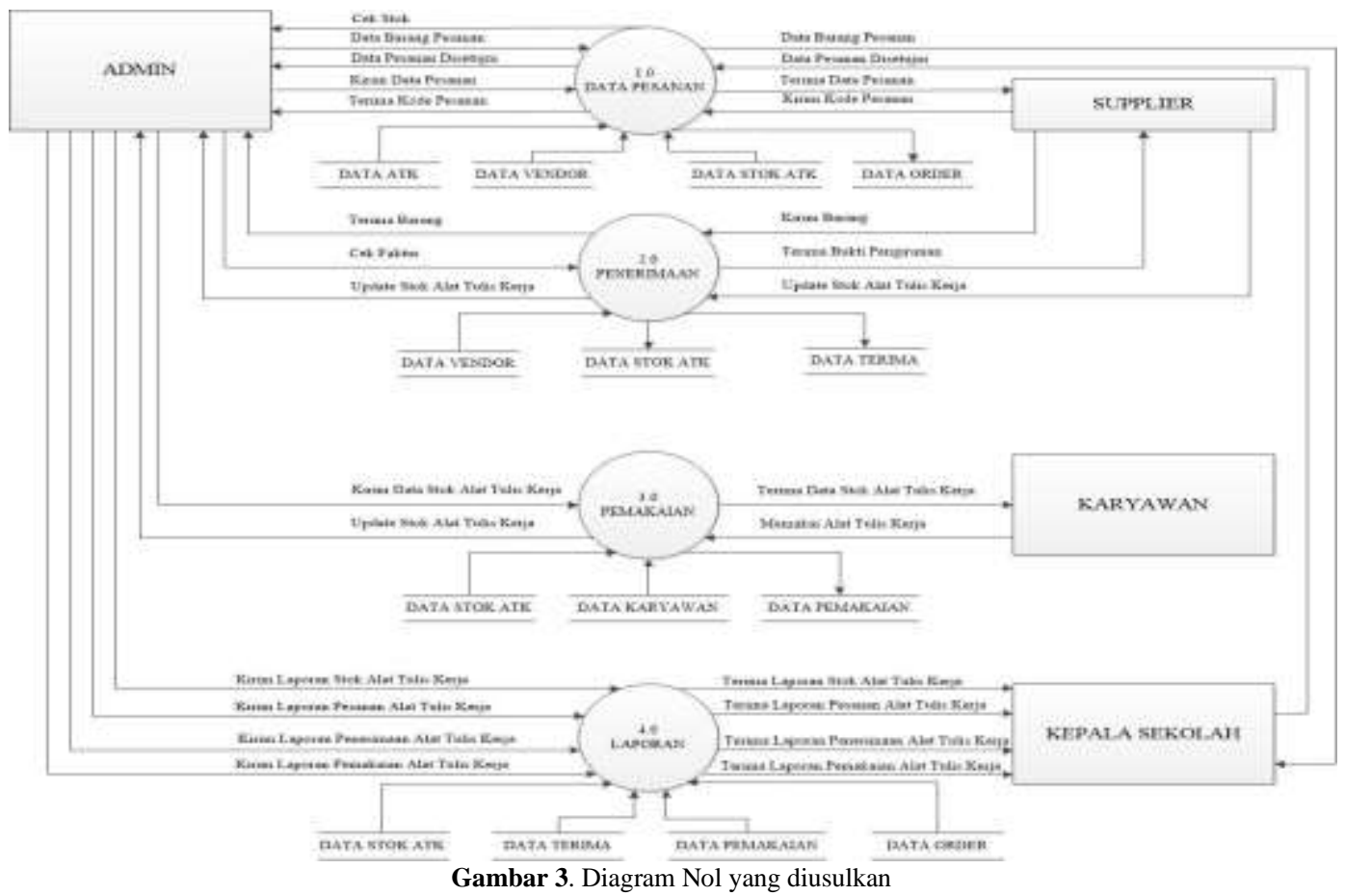

\section{Diagram Rinci}

Proses Rinci Level 1 Proses 1.0

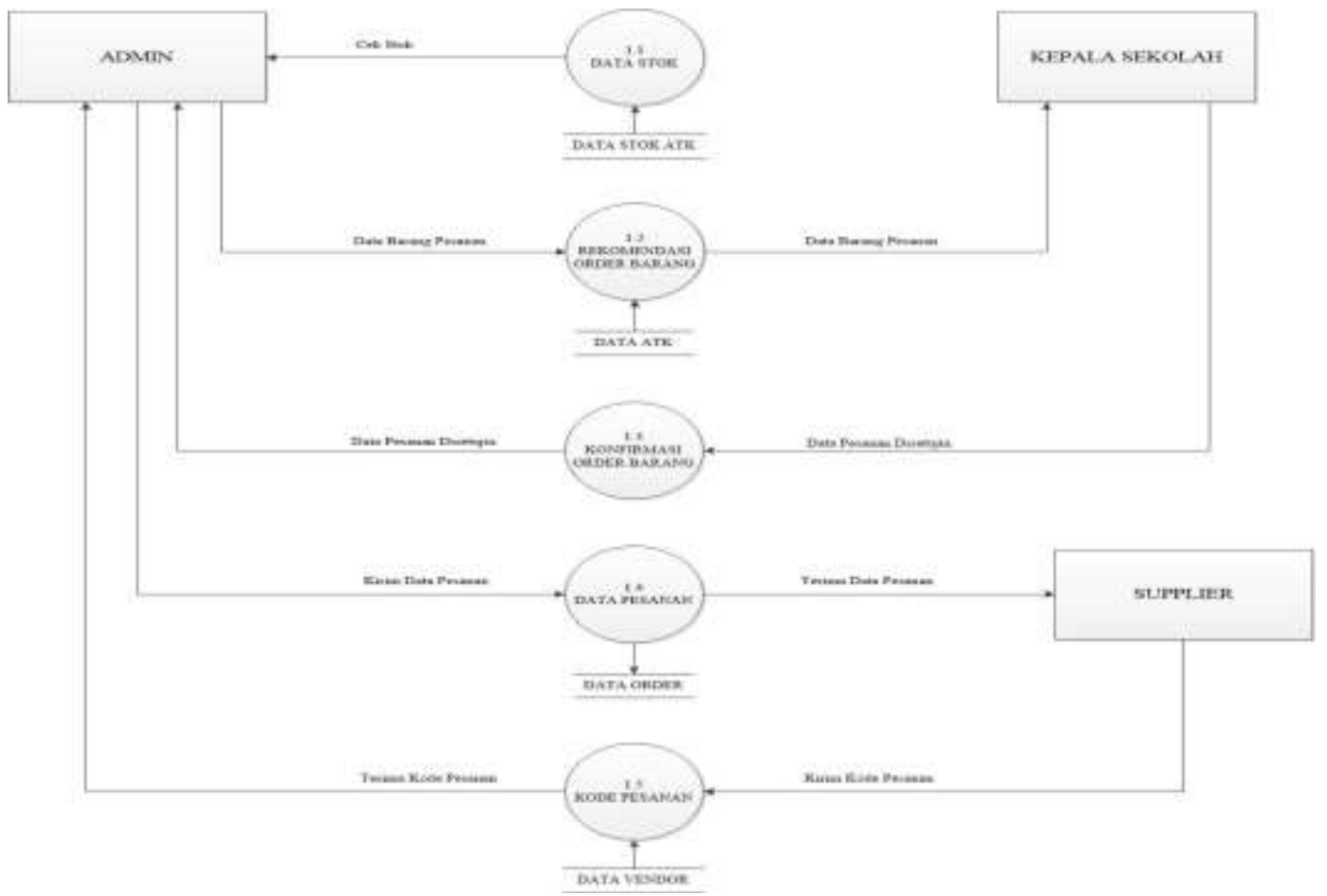

Gambar 4. Diagram rinci proses 1.0 
JRAMI (Jurnal Riset dan Aplikasi Mahasiswa Infarmatika)

Vol 이 No Ul Tahun 2020

e-ISSN : 2715-8756

\section{Diagram RinciLevel 1 Proses 2.0}

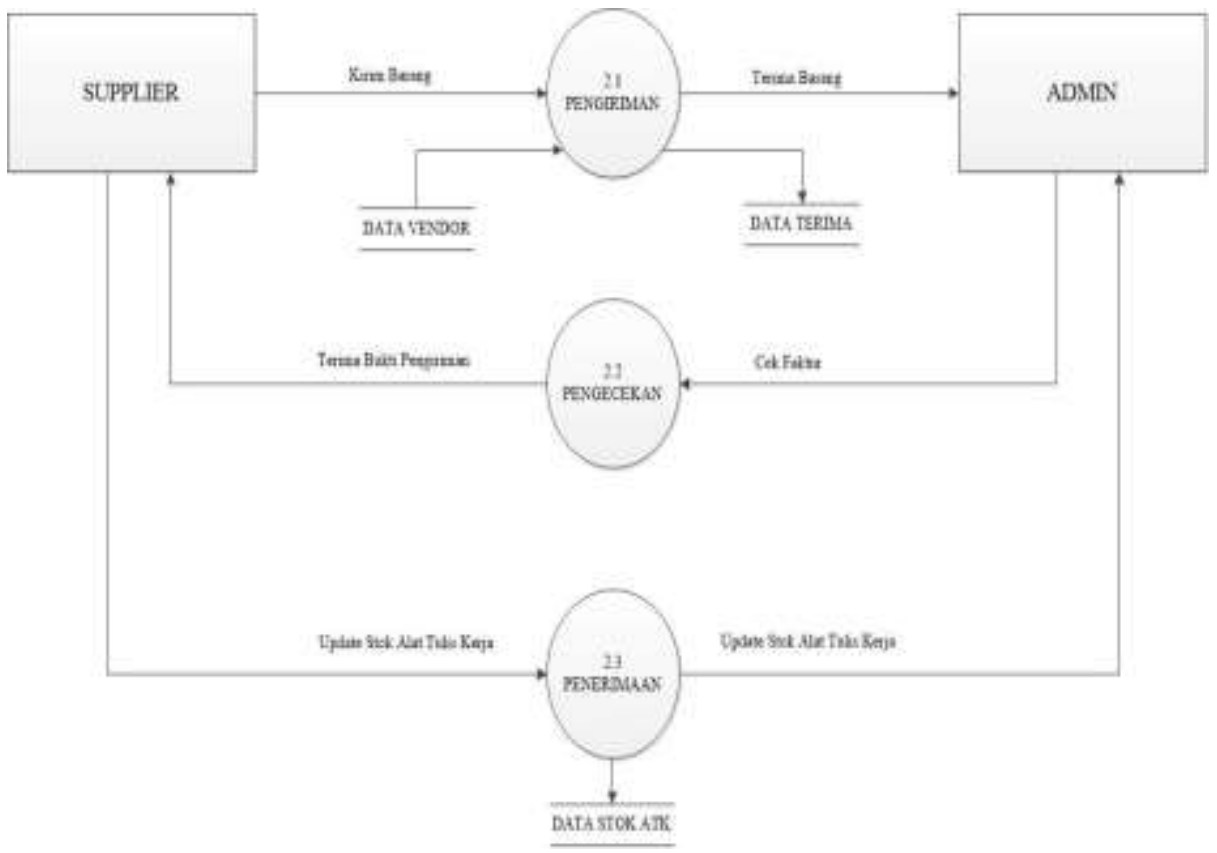

Gambar 5. Diagram rinci proses 2.0

Diagram RinciLevel 1 Proses 3.0

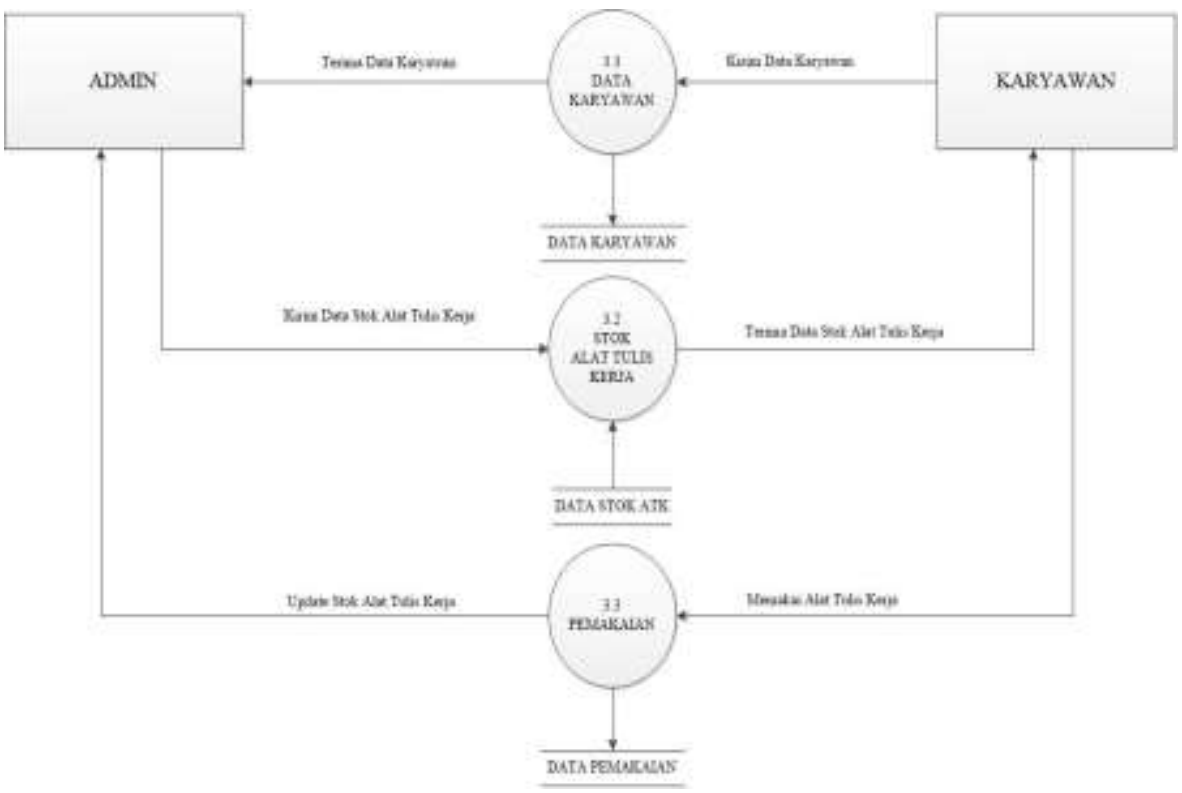

Gambar 6. Diagram rinci proses 3.0 
JRAMI (Jurnal Riset dan Aplikasi Mahasiswa Infarmatika)

Vol 이 No Ul Tahun 2020

e-ISSN : $2715-8756$

Diagram Rinci Level 1 Proses 4.0

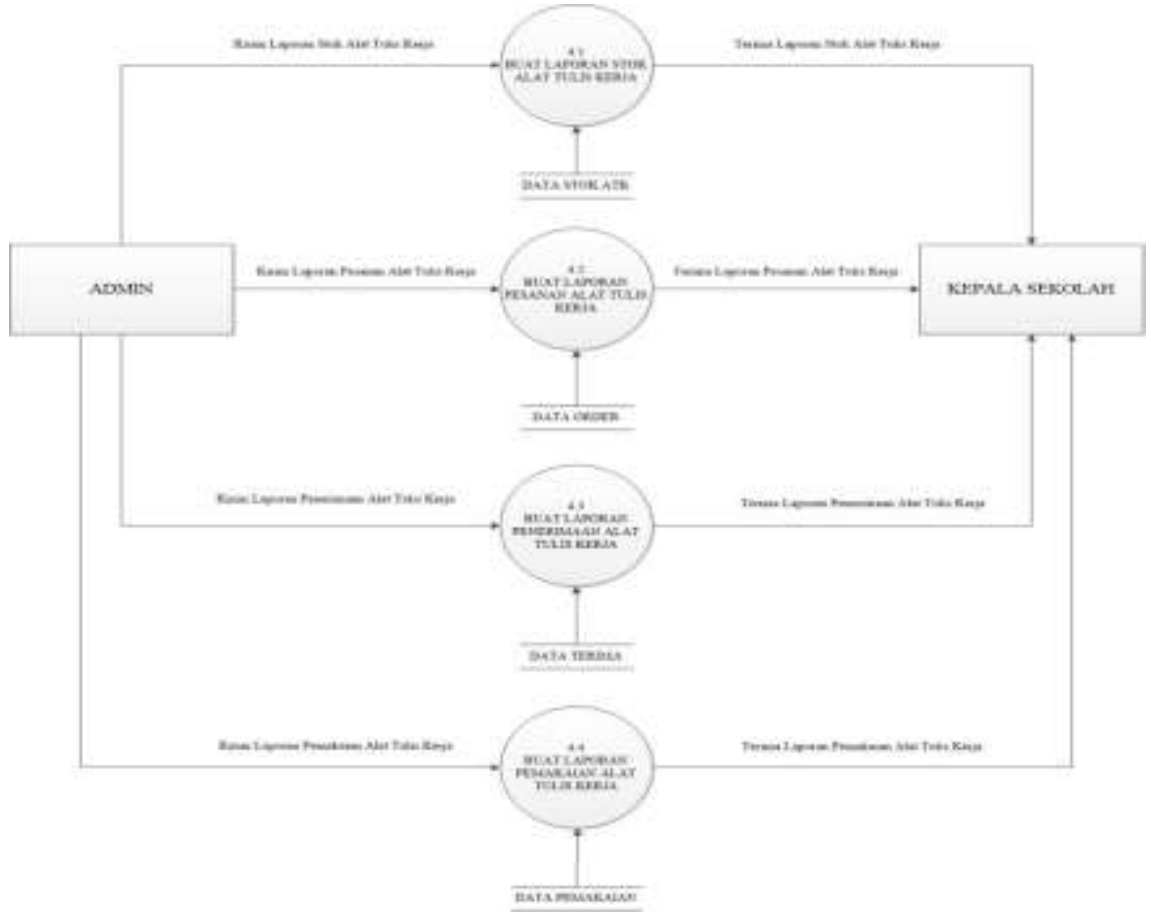

Gambar 7. Diagram rinci proses 4.0

\section{Rancangan Basis Data Sistem}

\section{ERD (Entity Relationship Diagram)}

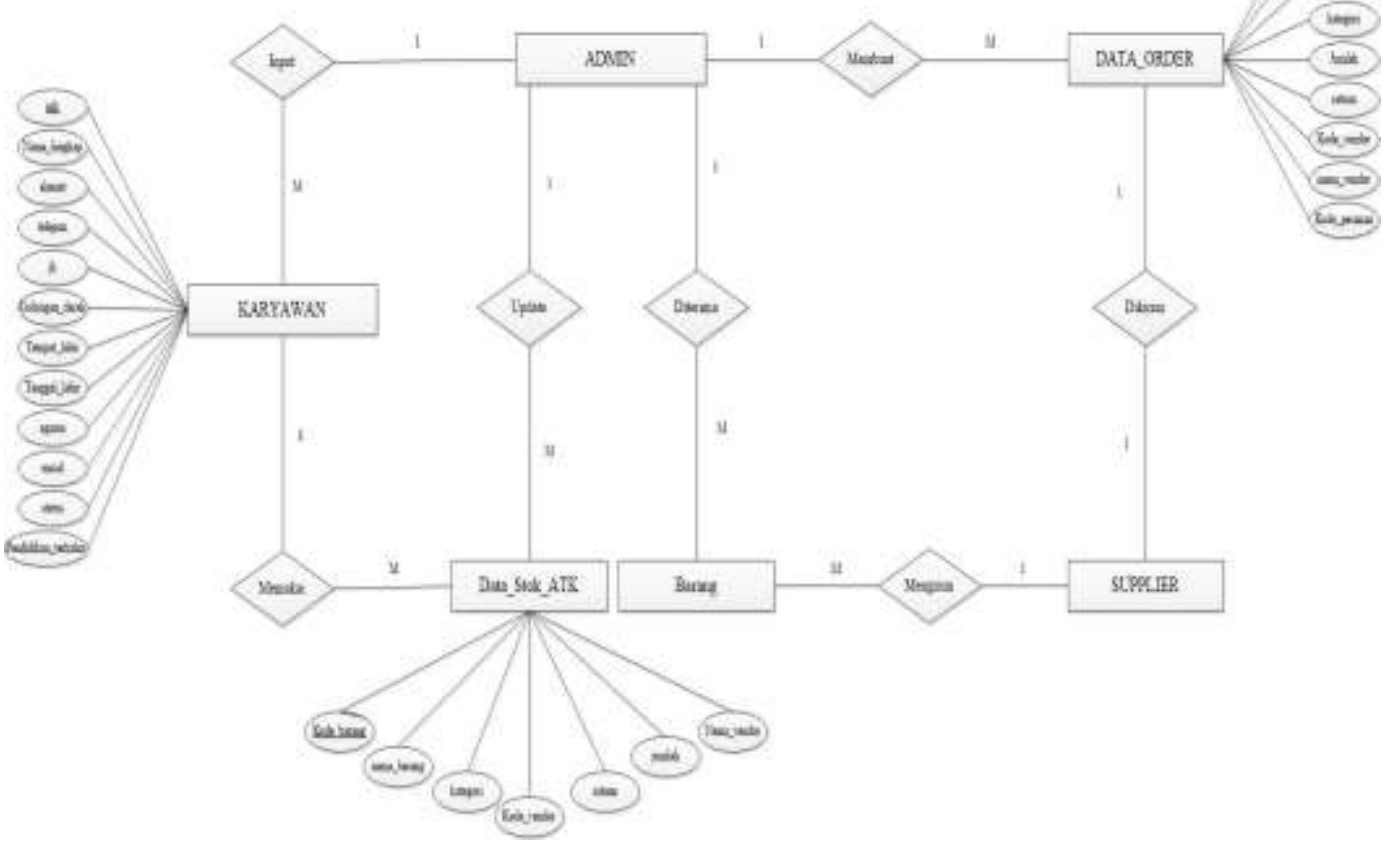

Gambar 8. Entity Relationship Diagram (ERD) Rancang Bangun Aplikasi Inventory Alat Tulis Kerja (ATK) 


\section{Tampilan Layar}

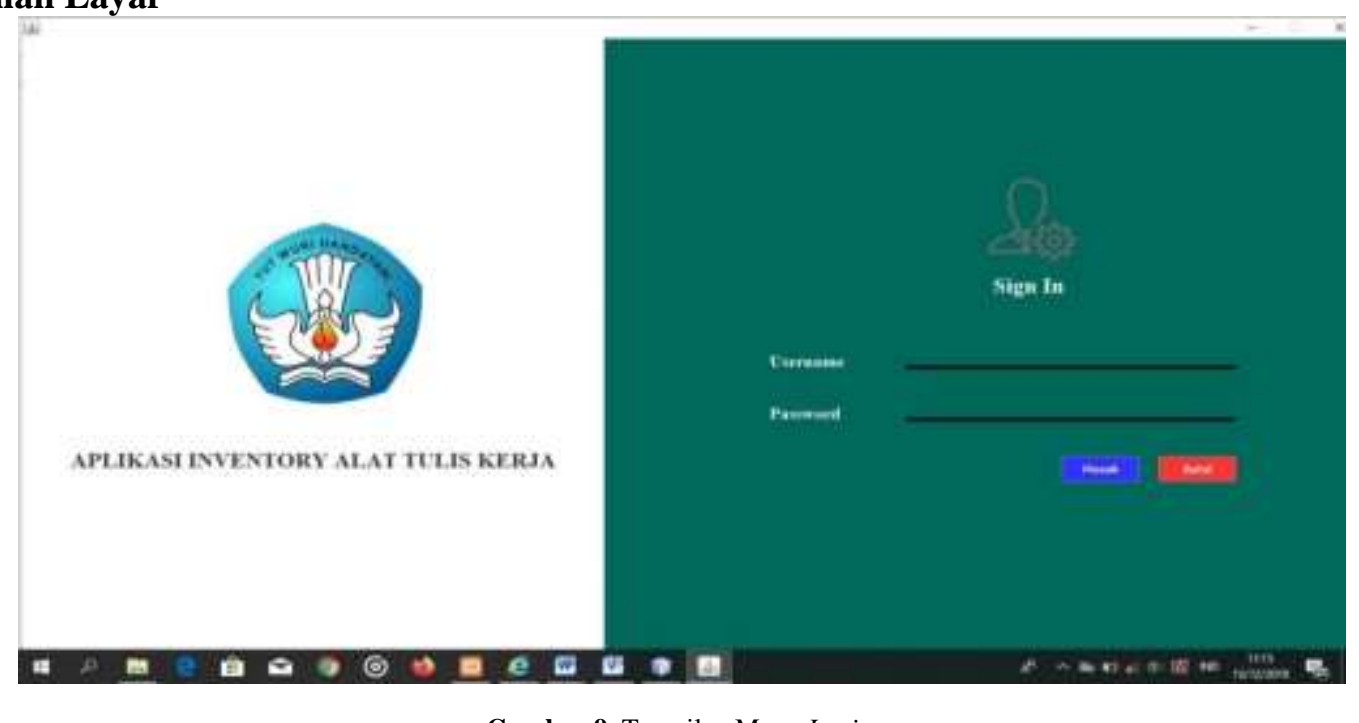

Gambar 9. Tampilan Menu Login

Rancangan ini terdapat pada awal program. Menu login digunakan sebagai kata kunci sebelum kita memasuki program utama.

\section{SIMPULAN}

Dengan dibangunnya suatu sistem aplikasi inventory ini, maka beberapa proses dalam kegiatan pengelolaan inventory sekolah untuk bagian staf tata usaha menjadi lebih terkomputerisasi dan efisien dalam pengelolaan data dan mengurangi kesalahan dalam mengolah data yang secara manual seperti sebelum aplikasi ini dibuat.

\section{DAFTAR PUSTAKA}

Haming, M., \& Nurnajamuddin, M. (2014). Manajemen Produksi Modern, Buku 1. Jakarta: Bumi Aksara.

Herjanto, E. (2010). Manajemen Operasi, ed: Revisi. Gramedia, Jakarta.

Utami, F., \& Asnawati. (2015). Rekayasa Perangkat Lunak (1st ed.). Yogyakarta: Deepublish.

Wicaksono, S. (2011). Konsep Dasar Rekayasa Perangkat Lunak. Jakarta: PT. Prestasi Pustakaraya.

Yanto, R. (2016). Manajemen Basis Data Menggunakan MySQL. Deepublish. 